\title{
FUTURE TRENDS IN FOOD TECHNOLOGY - NOVEL FOOD AND TRANSGENIC FOOD*
}

\author{
A review \\ J. FARKAS** \\ Department of Refrigeration and Livestock Products Technology, Szent István University, \\ H-1118 Budapest, Ménesi út 45. Hungary \\ (Received: 6 October 2000; accepted: 26 March 2001) \\ The paper reviews briefly the present status and future trends of some new, emerging food \\ preservation technologies and anticipates the major lines of developments in relation to functional \\ and transgenic foods. These topics of innovative food technologies and food products are of \\ particular importance in view of the European Union's regulation concerning "novel foods and \\ novel ingredients". The author considers the obstacles and the needs for more research and other \\ actions such as safety assessment and balanced communication to the public.
}

Keywords: food preservation, functional food, transgenic food

"Securing Food in Global Dimension" was rightly one of the mottos in the German Pavilion of the present EXPO 2000 at a time of explosively growing world population, which demands world-wide efforts to overcome problems related to the food supply. It is a peculiar contradiction that the centre of rapid population increase is in developing countries while food technologies bring forward newer opportunities in developed countries where food is abundant. Most developing countries are not able to undertake effective research and development of food technologies without the scientific and financial support of industrial countries. However, it is not only the bare quantity of food that counts. This is shown also by the first RTD co-operation programme of the EU's 5th Framework Programme, which is devoted to the problems related to "Quality of Life and Management of Living Resources", and the first key action of this programme is "Food, Nutrition and Health". "Health related quality of

* This paper was presented at the Symposium on "Nutrition and Food Safety", Hannover,

12 August 2000, within the framework of World Congress on Medicine and Health: "Medicine

Meets Millennium".

** To whom correspondence should be addressed.

Fax: 36-1-372-6321; E-mail: huto@omega.kee.hu 
life" is the perceived impact of health on a person's life. That concept evolved from the WHO's constitution defining health as a state of complete physical, mental and social well being and not merely the absence of disease. Safe food must be interesting, diversified and nutritionally balanced. Thus, not only is the EU programme in harmony with the agenda of the Symposium on "Nutrition and Food Safety" held in Hannover, 12 August 2000, in the frame of the World Congress on Medicine and Health: "Medicine Meets Millennium", but the organizers of that meeting recognized the significance of the three interrelated main research fields expressed by the above key action as well. These form one of the major areas where implementation of scientific knowledge obtained by RTD co-operation can best serve society's needs and the quality of life of not only the European consumer but of mankind in general. The above needs and the necessity for new and integrated concepts of food product innovation were also justly reflected by convening an international conference held this year in Porto under the title "Nutritionists Meet Food Scientists and Technologists", and have been addressed in the programme of the 5th Karslruhe Nutrition Symposium held October 2000.

As a food technologist, I should try - within the space limits for presentation - to restrict myself to the topics of

- some new food technologies which respond to the needs of our epoch, and

- foods with improved nutritional value.

Table 1

Article 1 of Regulation (EC) No. 258/97 of the EUROPEAN PARLIAMENT and of THE COUNCIL of 27 January 1997 concerning novel foods and novel food ingredients

Art. 1.1. "This Regulation concerns the placing on the market within the Community of novel foods or novel food ingredients.

Art. 1.2. "This Regulation shall apply to the placing on the market within the Community of foods and food ingredients which have not hitherto been used for human consumption to a significant degree with the Community and which fall under the following categories:

(a) foods and food ingredients containing or consisting of genetically modified organisms within the meaning of Directive 90/220/EEC;

(b) foods and food ingredients produced from, but not containing, genetically modified organisms;

(c) foods and food ingredients with a new or intentionally modified primary molecular structure;

(d) foods and food ingredients consisting of or isolated from micro-organisms, fungi and algae;

(e) foods and food ingredients consisting of or isolated from plants and food ingredients isolated from animals, except for food and food ingredients obtained by traditional propagating or breeding practices and having a history of safe food use;

(f) foods and food ingredients to which has been applied a production process not currently used, where that process gives rise to significant changes in the composition or structure of the foods or food ingredients which affect their nutritional value, metabolism or level of undesirable substances." 
In the latter context, I can't avoid to touch upon questions of the presently highly controversial topic of transgenic foods or food components. These topics of innovative food technologies and food products are of particular importance in view of the European Union's Regulation of 1997 concerning "novel foods and novel ingredients" (EC, 1997). The Regulation covers all foods and food ingredients that "have not hitherto been used for human consumption to a significant degree within the Community". The scope of this Regulation covers biological, chemical and technological innovations as quoted in detail in Table 1.

\section{New, emerging food preservation technologies}

Several well-established traditional processing options are available for the preservation of food. The most widely used among them, thermal processing, provides a high degree of microbial safety. It tends, however, to degrade the quality of foods to some extent. Freezing and distribution of frozen foods is an important technology which retains very well the nutritive quality, but changes the physical state and consumes a great amount of energy.

The present is a time of rapid change in the field of food technologies and the pace of change is increasing. Major motivations determining trends of development of new, emerging or future food technologies are those which signify responses of food science and industry to

- demands of consumers due to their changing lifestyles and expectations for

- fresher, more natural foods, which

- are less severely processed (less heat- or freeze-damaged),

- contain less preservatives, or are even free from "artificial" additives;

- nutritionally more advantageous food (e.g. containing less salt, less sugar or fat);

- safer food (posing no microbiological or chemical health hazards); and at the same time are

- foods convenient to handle ([semi]prepared or ready for consumption and with a sufficient shelf-life);

- needs for less energy requirement of processing;

- the necessity for lower impact on the environment.

These - to some extent conflicting - requirements motivated the introduction of less severe or "minimal processing" technologies such as controlled atmosphere storage of fruits and vegetables, and modified atmosphere packaging of foods, or the development of extended shelf-life refrigerated foods such as "sous-vide" cooked products. These requirements have also resulted in growing interest in new, "nonthermal" methods of food preservation such as 
- using new "biopreservatives" or new "protective cultures" utilizing their antagonism against pathogenic microorganisms;

$$
\text { or }
$$

- new "physical" technologies:

- ionising radiation treatment;

- high hydrostatic pressure treatment;

- high voltage electric field pulses

to inactivate pathogenic and spoilage microorganisms. (Other new physical methods of antimicrobial treatment such as high intensity light pulses, "manothermosonication" (combination of pressure, heat and ultrasound), or treatment with oscillating magnetic fields (FARKAS, 1997; GOULD, 2000) are either of more limited scope, or they are not yet sufficiently ready scientifically or technically for implementation).

Application of the technologies listed above offers various opportunities for mildly processed products by preserving their sensory quality, nutritional value and appearance. However, the application potential of any new technologies, which are coming from research laboratories and not "sanctioned" by centuries of empirical use, is influenced by many factors:

- technological feasibility;

- technical possibility;

- health impact

- wholesomeness of the product;

- occupational safety;

- environmental friendliness;

- economic feasibility (including their energy demand);

- infrastructural conditions/requirements;

- investment need and availability of investment power;

- political attitude;

- social consequences;

- psychological aspects/ risk-benefit perception.

Whereas the first four aspects listed can be scientifically studied, and clear-cut general answers can be given according to the status of science and technology of a given epoch, the other factors are very much interrelated and depend on local conditions.

A brief sketch of the state of the art of the new/emerging technologies can be given as follows:

"New" natural antimicrobial substances, particularly the use of bacteriocins produced by some lactic acid bacteria seem to gain a role in eliminating the risk of specific microorganisms in some foods (ABEE et al., 1995; KNORR, 1998). Some strains of lactic acid bacteria are considered as protective cultures, if they can be inoculated 
into certain foods, such as vacuum-packaged processed meats, and assert an inhibitory effect on pathogens during storage at abuse temperature, while having negligible effect on the sensory quality of the products (BREDHOLDT et al., 1999). Because of associated flavours that can alter the taste of food, future uses of plant-derived antimicrobials as food preservatives are not likely on their own, but as part of a preservation system (CHERRY, 1999).

Ionising radiation is a versatile form of processing energy used already in a wide range of non-food applications. It offers various technological benefits by reducing food losses and improving food safety (WILKINSON \& GOULD, 1996; PATTERSON \& LOAHARANU, 2000). Irradiation extends to solid and semi-solid foods like meat, poultry and seafood the same benefits as thermal pasteurization provided for liquids (SATIN, 1996). Radiation treatment at doses of 1.5 to $7 \mathrm{kGy}$ - depending on conditions of irradiation and of the food - can effectively eliminate potentially pathogenic nonsporeforming bacteria from suspected food products without affecting nutritional and technical qualities. These bacteria include both long-time recognized hazards such as Salmonella spp. and Staphylococcus aureus, as well as emerging or "new" pathogens such as Campylobacter spp., Listeria monocytogenes or Escherichia coli O157:H7 (FARKAS, 1998). In addition to control of the aforementioned bacteriological hazards, "radicidation" of perishable commodities can extend their shelf-life 2- to 3-fold, and inactivate food-borne parasites, the latter being of particular importance for developing countries. After decades of unprecedentedly intense and wide-ranging research efforts, food irradiation is now a well understood and controllable food processing technology supported by all relevant specialized agencies of the United Nations (the World Health Organization, the Food and Agriculture Organization and the International Atomic Energy Agency) and many national scientifically authoritative bodies in different countries. Its slow implementation can be explained by the long time, which was needed to demonstrate adequately the safety and wholesomeness of irradiated food, the lack of readily available radiation facilities and their investment-demanding character, as well as an inadequate awareness of problems, which justify the use of this technology. The safety and nutritional adequacy of irradiated food have been well established (WHO, 1994; DIEHL, 1995), the technology is ready to use technically, and the need to improve the microbial and parasitic safety of food became a major driving force behind the implementation of food irradiation in both developed and developing countries. When irradiation is perceived as an adjunct to, but not a replacement for, GMP, it can serve as a "critical control point" in the Hazard Analysis Critical Control Points system of safety management, a concept becoming mandatory in more and more countries.

The advantage of high hydrostatic pressure (HP) treatment (up to $900 \mathrm{MPa}$ [i.e. as high as 9000-times the atmospheric pressure] for several minutes) is that it treats all parts of a high moisture food equally (high isostatic pressure) and it is attractive from 
the point of view of food product quality (BARBOSA-CANOVAS et al., 1997). At present its application is limited to a pasteurization-like process for certain foods in which bacterial spores are not a problem (low-pH products) or which have a limited chill shelflife. Success of its further development depends on effective control by appropriate combination treatments and additional research for careful establishment of performance criteria for reduction of the number of relevant pathogens by a required safety factor (Gould, 2000). Due to these facts, and because of costs involved in HP pasteurization/sterilization of foodstuffs, this process will remain probably rather specialised and will only be used to preserve foods for which a premium price can be obtained.

High voltage electric field pulses (HELP) to effect non-thermal inactivation of microorganisms in foods was also explored, and these studies led to the development of prototype and industrial scale devices recently (BARBOSA-CANOVAS et al., 1997). HELP treatment is the application of pulses of very high field strength $\left(2-5 \mathrm{~V} \mathrm{\mu m}^{-1}\right)$ for a very short time (microseconds) to foods between two electrodes. The treatment requires fairly complex electronic and fluid handling systems. Studies on combination processes have shown potentially useful synergies because "electroporated" bacterial cells become much more sensitive than untreated cells (e.g. to bacteriocins). The application of HELP will probably be limited to liquid foods or liquids containing small particulates (GOULD, 2000). There are still, however, considerable knowledge gaps that will need to be addressed, and regulatory hurdles to be overcome, before commercialisation of the technology, but HELP products might be in the market place in 10 years' time.

All these technologies might be utilized even more efficiently in rational combinations with other preservative treatment(s).

Among future challenges for food science in the field of more efficient improvement of microbial safety and quality maintenance of food are

- better understanding of factors affecting the establishment, survival and growth of food-borne microorganisms by multidisciplinary research on

- physiology of microorganisms;

- development of predictive models for their growth, survival, inactivation or the shelf-life of foods;

- effect of food structure on its interactions with microorganisms;

- application of molecular biology for improved characterization, typing and detection of important microorganisms;

- better utilization of synergistic interactions of "combinations"/ "hurdle effects", but avoiding stress adaptation.

Advances in predictive microbiology will assist optimization of existing processes and formulation of alternative processes with regard to their effect on food safety. If the microbiological feasibility of new physical technologies is carefully established and, 
particularly, new combination approaches are developed and proven effective, the opportunities for the use of some of the new techniques are likely to expand in the future. From the food industry side, there is a need to "metabolise" the novelty of the aforementioned technologies to appreciate their potential over the hurdles that must be overcome.

\section{Food with improved nutritional value}

Until recently, health aspects of food were mainly thought of as the absence of detrimental components, in particular additives and unwanted compounds. In the past years, however, it has become evident that some naturally occurring components of certain foods can help to maintain a state of well being and health through optimising our body functions or to reduce risk of chronic diseases, such as certain cancers and coronary diseases (ROBERFROID, 1999). This is particularly important in that most countries are experiencing a considerable rise in the proportion of elderly people, and proper nutrition can assist us to live not only longer, but in better health (PSZCZOLA, 1999).

In addition, many technological innovations are related to the recognition of the important role of food in promoting and sustaining health, resulting in the concept of "nutraceuticals" and "functional foods". Nutraceuticals are those food components, which play particular roles in maintaining health. They originate mainly from plants, i.e. they are "phytochemicals". Functional foods are foods characterized by the presence of one or more components having beneficial physiological effect and being effective in the maintenance of good health. In one group of functional foods live bacteria (certain lactobacilli and bifidobacteria) provide the main beneficial effect. These foods are called probiotics (KNORR, 1998; SANDERS, 1999). Other functional foods contain prebiotics, i.e. substances that facilitate growth of the beneficial bacteria in the intestinal tract of the consumer. This interaction between food, nutrition and health is a new challenge for both food science and the food industry and it represents a positive approach to "optimizing" nutrition. It is important, however, that claims on healthpromoting effects have sufficient scientific substantiation. It is important that health authorities should establish criteria for mandatory qualification of functional foods. Development of functional food should not be only a marketing claim, but rather a scientific challenge. The presence of a bioactive compound in a food does not necessarily ensure that it will be biologically active when it is consumed. The benefits of the "functional foods momentum" will not be realized unless scientifically sound and non-misleading messages are provided to consumers (MILNER, 1999).

Food can be said to be "functional" if it is satisfactorily demonstrated to affect beneficially one or more target functions in the body beyond adequate nutritional effects, in a way which is relevant to either the state of well-being and health or the 
reduction of the risk of a disease (ROBERFROID, 1999). A functional food can be a natural food, a 'modified' traditional food or a 'novel food' as defined in the aforementioned EU Regulation.

The production of functional foods happens by

- eliminating a component causing deleterious effect to the consumer (e.g. an allergenic protein);

- increasing the concentration of a natural component which induces beneficial effects;

- adding a natural substance which is not normally present, but for which beneficial effects have been demonstrated;

- replacing a component which causes deleterious effects by a component with beneficial effects;

- improving the bioavailability of food components with beneficial effects.

Functional foods must remain foods, they are not medicaments, but part of nutrition/diet. Because functional food development targets healthy subjects, proving their effects' statistical significance requires a special methodological approach (MÉANCE et al., 1999). It will become increasingly important to

- identify the mechanism of action of the active components in functional foods;

- clarify the impact that commercial processing and home-processing have on bioactive components within foods;

- optimize process parameters for maximal retention and increased bioavailability of beneficial compounds;

- understand the dynamic interactions that occur among the various components of not only the food but with the other constituents of the entire diet;

- investigate the interaction between diet and human intestinal microflora and its implication for health.

\section{Transgenic food}

While consumers accept the functional food concept remarkably readily, the acceptance of novel foods as they are defined according to the EU Regulation (EC, 1997), and particularly transgenic food, is controversial.

Conventional breeding can be used to transfer genes only between sexually compatible organisms. Complementary to conventional breeding techniques, gene technology allows the transfer of genes between unrelated species. Thereby, breeding targets can also be achieved more quickly both in plant and animal breeding. This is one of the key, but hotly debated technologies of our times. Important topics that need to be addressed vary from legislation, such as labeling requirements, to safety and 
environmental issues. Concerns about application of this agricultural biotechnology are on the ecological impact of growing genetically modified foods, the impact of these crops on biological diversity, and on the safety of food supply, or the development of resistance by insect pests. However, the potential of the agricultural new biotechnologies is enormous also for developing countries. Therefore, questions about agricultural biotechnology must be addressed for people in both developed and developing countries, as we have to address the issue of food security for a world population of some 9000 million people in the year 2050. Furthermore, genetic engineering is not just a new technology for crop improvement, it is a powerful research tool that is helping to provide fresh and better insights of molecular mechanisms involved in biological processes.

It is forecasted that in the next decade about four dozens of agricultural crops will be genetically modified. It is estimated that already 8.3 million ha of genetically modified corn ( $20 \%$ of the total cultivated area) were planted in the US in 1999, and that more than 66 million ha will be used to cultivate transgenic plants by 2005 in North America (GACHET et al., 1999). No less remarkable are the opportunities and research results in the field of food biotechnology by improving microorganisms used in food fermentations, and on the exploitation of microorganisms for the manufacture of food ingredients.

Without venturing more deeply into this enormously complex problem-area where I have no expertise, I should like to limit myself to those aspects of transgenic food or food components which are relevant to the potential improvement of nutritional value and technological functionality of food or food components.

There are already a number of foods on the market which are produced using genetically modified organisms or containing GM ingredients e.g. chymosin used in cheese making, use of GM tomatoes in paste, and GM soybean and corn products. Thus, most of the transgenic products to date have been developed for agricultural and processing efficiency, and not yet with direct consumer benefits in mind, such as improved taste and higher nutritional value. I share the views of those who consider that a "second generation" of transgenic crops should be devoted to achieve these advantageous compositional changes in order to serve the increased interest in functional foods and passing the benefit on to the consumer. Food R\&D in the 21st century should also support consumer oriented product development because it has the potential to become part of the health care system. Several transgenic foods are now under development, which aim to develop properties of nutritional significance. Some examples:

- producing rape seed and corn with nutritionally more favourable oil composition (containing negligible levels of erucic acid);

- spinach and lettuce accumulating less nitrate; 
- potato richer in starch, thus absorbing less fat when fried;

- certain cereals with increased lysine content;

- certain legumes with increased methionine content;

- rice not producing an allergen;

- "yellow rice" capable of synthesising beta-carotene;

- strawberry and broccoli producing higher levels of anticancer and antioxidant agents (GACHET et al., 1999; HOGAN, 1999; LIU, 1999).

Safety evaluation, however, is a key issue, which must be addressed in relation to the development of novel or improved foods. Guidance on this complex topic is available from a report of a Joint FAO/WHO Consultation (1996) on "Biotechnology and Food Safety" (FAO/WHO, 1996).

Regarding safety assessment of novel food in relation to nutrition, special attention must be paid also to allergenicity of those foods which are produced using this modern biotechnology to avoid the potential appearance of a major food allergen in a product that is normally allergen free.

A summary of results of an EU project on the development of new methods for safety evaluation of transgenic food crops has been presented at the 3rd Karlsruhe Nutrition Symposium in October 1998 (NOTEBORN, 1998), while the International Life Science Institute recently published "Consensus Guidelines" on the safety assessment of viable genetically modified microorganisms used in food (ILSI, 1999).

Principles for approving novel food, particularly genetically modified raw materials, were fundamentally different in North America than in the European Union, which created complications for the food industry and trade. The labeling of genetically modified organisms was not mandatory in the US, where the FDA labeling policy requires "biotech foods" to be labeled only if they are significantly altered. In response to a request from FDA for comments from the public on the Agency's current regulatory regime for food biotechnology and labeling, in formal comments submitted to FDA, the National Food Processors Association (NFPA) called, early in the year 2000, for a compulsory notification process prior to the marketing of new "biotech" food products. The producers of such foods should file with FDA summary documentation to support the determination of safety for the biotech food (NFPA, 2000). NFPA further supports the use of voluntary labeling of foods to indicate the presence or absence of bioengineered ingredients. The European Union "Novel Food Regulation" established a system for formal, mandatory pre-market evaluation and approval for most innovative foods and food production processes, placing particular emphasis on genetically modified products. It requires additional specific labeling of "any characteristic or food property such as composition, nutritional value or nutritional effects, or intended use which renders the food no longer equivalent to its conventional counterpart." Although this EU Regulation provides broad guidance, it leaves the door wide open to 
interpretation and it is unlikely to stimulate European innovation and competitiveness (HugGetT \& Conzelmann, 1997). The recently finalised "White Paper on Food Safety" of the Commission of the European Communities states that "the Community provisions governing novel foods have to be tightened and streamlined", and it describes actions to this end (EC, 2000).

This is an area where the future depends on acceptance of rational, science-based weighting of risk with benefits and the provision of accurate and unbiased information to the consumer. The risk of not using technologies and of alternative methods should be also concerned. However, there is a multitude of ethical and social issues to be considered (MOSELEY, 1999). There appears to be an even greater aversion among consumers towards the genetic engineering of animals than towards plant biotechnological programmes (MENRAD, 1998).

To analyse the risks of transgenic foods, the FAO/WHO Codex Alimentarius Commission established an "Ad Hoc Intergovernmental Task Force on Foods derived from Biotechnology" (FAO, 2000), which held its first meeting in Japan at the time when I was preparing this paper. This Task Force uses the concept of "substantial equivalence" established by the Organization for Economic Cooperation and Development as a central to the process of risk assessment and will review other methods for science-based risk assessment. It is expected that the above Codex Task Force will come up with a Codex' standard on transgenic foods. The "precautionary approach" adopted by the recently signed UN Protocol on Biosafety (Cartagena Protocol) can be used by governments in their risk management relevant to the above risk assessment. Identifying and labeling foods as having been derived from biotechnology can form a risk management system that will both protect the health of consumers and promote fair trade practices (FAO, 2000).

In my view, trusting science is one of the key factors for developing new technologies and evaluating new products, regardless of the technology or practices concerned. Unfortunately, however, food irradiation, biotechnology, and confidence in food safety are all media-vulnerable issues. Future developments will depend on more effective and balanced communication to the public, effectively addressing social, ethical and political issues, scientific questions and regulatory needs. It is important to understand the way that people perceive risk psychologically. Consumer acceptance of new processes is likely to be increased when a direct consumer benefit is recognized. However, huge information gaps exist among scientists and particularly between scientists and consumers. To match the promise offered by technological advances and optimize nutrition, the overcoming of barriers in psychological and - as a consequence - political feasibility is required. This needs not only research efforts but education in all stages of the food chain and in all sectors of communication (HOBAN, 1999), because "if we fail to train we fail to convince, if we fail to convince we fail". 
The author gratefully acknowledges the valuable advice and ideas of Prof. F. KÄFERSTEIN, Prof. G. BíRó and Dr. D. BÁNÁTI.

\section{References}

Abee, T., Krochel, L. \& Hill, C. (1995): Bacteriocins: modes of action and potentials in food preservation and control of food poisoning. Int. J. Fd Microbiol., 53, 43-52.

Barbosa-Canovas, G. V., Pothakamury, K. R., Palou, E. \& Swanson, B. G. (1997): Nonthermal preservation offoods. 2nd ed., Marcel Dekker, Inc., New York.

Bredholdt, S., NesBAKKen, T. \& HolcK, A. (1999): Protective cultures inhibit growth of Listeria monocytogenes and Escherichia coli $\mathrm{O} 157: \mathrm{H} 7$ in cooked, sliced, vacuum- and gas-packaged meat. Int. J. Fd Microbiol., 53, 43-52.

ChERry, J. P. (1999): Improving the safety of fresh produce with antimicrobials. Fd Technol., 53 (11) 54-59.

DIEHL, J. F. (1995): Safety of irradiated foods. 2nd ed., Marcel Dekker, Inc., New York.

EC (1997): Regulation (EC) No. 258/97 of the European Parliament and of the Council of 27 January 1997 concerning novel foods and novel food ingredients. Off. J. Eur. Commun., No. L43/1-6, 14.2.97.

EC (2000): White paper on food safety. COM (1999) 719 final. Commission of the European Communities, Brussels, 12 January 2000.

FAO (2000): Task force analyses the risks of foods derived from biotechnology. FAO News \& Highlights, March 14, 2000.

FAO/WHO (1996): Biotechnology and food safety. Report of a Joint FAO/WHO Consultation, Rome, Italy, 30 September to 4 October 1996.

FARKAS, J. (1997): Physical methods of food preservation. -in: DoYle, M., Beuchat, L. R. \& MonTVILLE, T. J. (Eds.), Food microbiology: fundamentals and frontiers. ASM Press, Washington, D. C., pp. 497-519.

FARKAS, J. (1998): Irradiation as a method for decontaminating food. A review. Int. J. Fd Microbiol., 44, 189-204.

Gachet, E., Martin, G. G., Vigneau, F. \& Meyer, G. (1999): Detection of genetically modified organisms (GMOs) by PCR: a brief review of methodologies available. Trends Fd Sci. \& Technol., 8, 380-388.

Gould, G. W. (2000): New and emerging physical methods of preservation. -in: LuND, B. M., BAIRDPARKER, T. C. \& Gould, G. W. (Eds.) The microbiological safety and quality of food. Vol. 1, Aspen Publishers, Inc., Gaithersburg, Maryland, pp. 277-293.

Hoban, T. J. (1999): Consumer acceptance of biotechnology in the United States and Japan. Fd Technol., 53 (5) 50-53.

HoGan, S. (1999): "Yellow rice" to prevent vitamin A deficiency. Bioforum int., 3, 100-101.

Huggett, A. C. \& CONZELman (1997): EU regulation on novel foods: Consequences for the food industry. Trends Fd Sci. \& Technol., 8, 133-139.

ILSI (1999): Safety assessment of viable genetically modified micro-organisms used in food. International Life Sciences Institute, July 1999.

KNORR, D. (1998): Technology aspects related to microorganisms in functional foods. Trends Fd Sci. \& Technol., 9, 295-306.

LIU, K. (1999): Biotech crops: products, properties and prospects. Fd Technol., 53 (5) $42-48$. 
MÉance, S., Massad, L., CÉcile, A. \& Postaire, E. (1999): Specificity of clinical trials for functional foods. -in: LÁsztity, R., Pfannhauser, W., Simon-Sarkadi, L. \& TÖmÖsköZi, S. (Eds.) Proceedings of EURO FOOD CHEMX: Functional Foods - A new challenge for the food chemists, 22-24 Sept. 1999, Budapest. Budapest, Hungary, Vol. 1, pp. 18-29.

MENRAD, K. (1998): Consumer attitudes of modern biotechnology in the agro-food sector. -in: GAUKEL, V. \& SPIESS, W. E. L. (Eds.) Proceedings, 3rd Karlsruhe Nutrition Symposium, 18-20 October 1998. BFE, Karlsruhe, Part 2, pp. 329-339.

MiLner, J. A. (1999): Functional foods - The US perspective. -in: LÁszTiTY, R., PFANNHAUSER, W., SimONSARKADI, L. \& TÖMÖSKÖZI, S. (Eds.) Proceedings of EURO FOOD CHEMX: Functional Foods - A new challenge for the food chemists, 22-24 September 1999, Budapest. Budapest, Hungary, Vol. 1, pp. 46-55.

Moseley, B. E. B. (1999) The safety and social acceptance of novel foods. Int. J. Fd Microbiol., 50, 25-31.

NFPA (2000): NFPA calls for "compulsory notification" on biotech foods. News Release, January 14, 2000. National Food Processors Association, Washington, D. C.

NOTEBORN, H. P. J. M. (1998): Development of new methods for safety evaluation of transgenic food crops. -in: Gaukel, V. \& SPIESS, W. E. L. (Eds.) Proceedings, 3rd Karlsruhe Nutrition Symposium, 18-20 October 1998. BFE, Karlsruhe, Part 2, pp. 59-69.

PATterson, M. F. \& LoAharanu, P. (2000): Irradiation. -in: Lund, B. M., BAIRD-PARKER, T. C. \& Gould, G. W. (Eds.) The microbiological safety and quality of food. Aspen Publishers, Inc., Gaithersburg, Maryland, Vol. 1, pp. 65-100.

PsZCZOLA, D. E. (1999): It's never too late: Ingredients for the aging. Fd Technol., 53 (5) 60-68.

RoBerfroid, M. B. (1999): What makes food functional? -in: LÁSZTity, R., PFANNHAUSER, W., SimONSARKADI, L. \& TÖMÖSKÖZI, S. (Eds.) Proceedings of EURO FOOD CHEMX: Functional Foods - A new challenge for the food chemists, 22-24 September 1999, Budapest., Budapest, Hungary, Vol. 1, pp. 3-10.

SANDERS, M. E. (1999): Probiotics. Fd Technol., 53 (11) 67-77.

SATiN, M. (1996): Food irradiation. A guidebook. 2nd ed., Technomic Publ. Co., Inc., Lancaster/Basel.

WHO (1994): Safety and nutritional adequacy of irradiated food. World Health Organization, Geneva.

WiLKINSON, V. M. \& GouLD, G. W. (1996): Food irradiation: A reference guide. Butterworth-Heinemann, Oxford. 